\title{
Diversity and distribution of physical dormant species in relation to ecosystem and life-forms
}

\author{
Ganesh K. Jaganathan, Danping Song and Baolin Liu \\ Department of Biothermal Engineering, University of Shanghai for Science and Technology, Shanghai 200093, China
}

Article history

Received: 04 February 2017

Accepted: 20 March 2017

Published: 01 April 2017

(C) Jaganathan et al. (2017)

Editor

K. K. Sabu

Publisher

Horizon e-Publishing Group

Corresponding Author Ganesh K. Jaganathan $\bigotimes_{\text {iganeshcbe@gmail.com }}$

\begin{abstract}
Impermeable seed/fruit coat, i.e. physical dormancy (PY) occurring only in several genera of 18 angiosperm families plays an important role in controlling seed persistence and germination timing. It has been theoretically speculated that PY is more prevalent in drylands than in moist vegetation zones, but unequivocal support for this assertion is currently unavailable. The broad objective of this contribution was to examine the distribution of PY on the various vegetation of tropics and temperate ecosystems using a data set of 13, 792 species. The number of species with PY in tropics (19\%) is higher than the number of PY species in the temperate ecosystem (15\%). However, in both tropics and temperate, there is a clear trend that PY is less common in moist and low-temperature vegetation zones compared with dry and high-temperature vegetation. In tropics, PY is more prevalent in dry woodlands (33\%) and tropical deciduous forests (27.3\%) compared with the evergreen rain forest (9\%). Similarly, in the temperate zone, dry vegetation with seasonal rainfall such as Matorral (22.3) and deserts (19.5\%) have a higher number of PY species compared with moist warm woodlands $(8.1 \%)$ and deciduous forest $(9 \%)$. Although PY is a trait found in various life-forms, it appears to be less common in trees, particularly of the temperate zone. We discuss the ecological adaptation of PY in the dry ecosystem and consider the mechanism of persistence and dormancy break in PY and physiological dormant (PD) species.
\end{abstract}

Keywords

Adaptation; dry ecosystem; germination; impermeable seed coat; persistence

Jaganathan, G. K., Song, D. and Liu, B. 2017. Diversity and distribution of physical dormant species in relation to ecosystem and life-forms. Plant Science Today 4(2): 55-63. http://dx.doi.org/10.14719/pst.2017.4.2.293

\section{Introduction}

Impermeable seed/fruit coat, i.e. physical dormancy (PY) occurring only in several genera of 18 angiosperm families is an important functional trait controlling the persistence of seeds in soil and germination timing (Baskin and Baskin 2014; Baskin and Baskin 2004; Long et al. 2015). The onset of impermeability in species with a known history of PY begins during the end of maturation drying, where the palisade layer becomes impermeable to water and the seed coat structures that remained open during the seed development such as micropyle also close (Egley 1979; Geneve 2009).
Many seeds dispersed in the impermeable state persist in the soil until suitable environmental conditions open the specialized structures of the seed coat, often referred to as 'water-gap', e.g. lens in Fabaceae (Gama-Arachchige et al. 2013; Van Assche et al. 2003). A range of environmental conditions occurring in different ecosystems is identified to make seeds permeable (Rolston 1978). In tropical environments, high summer temperatures, diurnal temperature fluctuation are the important cues that break dormancy, whereas, in the temperate ecosystems freeze-thaw cycle, low winter temperatures could break the dormancy 
and synchronize the germination timing with the growing season (Baskin and Baskin 2014). In addition to these environmental cues, other factors such as fire and passage of seeds through animal gut could also break dormancy (Baskin et al. 2000; Jaganathan et al. 2016). Germination of PY seeds begins immediately after 'water-gap' is opened, only if the embryo has no physiological dormancy (PD), i.e. combinational dormancy (PY+PD), which also requires additional dormancy breaking cues (Baskin and Baskin 2004).

The growing body of literature on physical dormant seeds clearly suggest that there is a strong correlation between moisture content of the seeds and the inception of impermeability (GamaArachchige et al. 2011; Geneve 2009; Hay et al. 2010; Mai-Hong et al. 2003). The moisture content at which the seeds become impermeable varies between species, but mostly in the range of $15-10 \%$ f.wb (Hay et al. 2010). Despite this variation, information available on a handful of species unequivocally confirm that seeds collected early in the maturation drying and kept at higher relative humidity remained permeable throughout storage, as opposed to the seeds stored at lower relative humidity environment, which induced impermeability (Barrett-Lennard and Gladstones 1964; Gladstones 1958). This understanding has led to the implication that the maternal environment at which seeds develop plays an important role in determining whether the seeds would develop impermeability or not (Hudson et al. 2015; Jaganathan 2016). For example, in certain moist environments with high rainfall throughout the year and high humidity, the moisture content of the seeds during maturation drying are kept higher than the level at which the seed coat become permeable. Conversely, dry ecosystems with seasonal rainfall and low humidity are likely to dry the seeds during development leading to impermeability.

Furthermore, in the moist ecosystem, there is no obvious need for the seeds to germinate at a particular period of time because the conditions conducive to germination such as water and appropriate temperature are available throughout the year (Sautu et al. 2006; Vázquez-Yanes and Orozco-Segovia 1993). Thus, many seeds are nondormant and are shed at relatively higher moisture content, i.e. desiccation sensitive or recalcitrant seeds, for which the germination begins without any delay after maturation (Dickie and Pritchard 2002; Hong et al. 1998; Pritchard et al. 2004; Tweddle et al. 2003). However, in the ecosystem with dry and asesonal rainfall, conditions favorable for germination occurs only at a particular period of year and persistence of seeds in the soil until the rainy season is an important trait for species colonization (Garwood 1983; Khurana and Singh 2001). Impermeable seeds are long-lived in soil and many of them possess the ability to form long-term soil seed banks (Baskin and Baskin 2014; Egley and
Chandler 1983; Shen-Miller et al. 1995). Thus, by producing both permeable and impermeable seed coats in various proportions based on the ecosystem, species can spread the risk of germination across space and time (Baskin et al. 2000). This favors the secondary dispersal of seeds to open sites and provide an opportunity to colonize in new environments (Chambers and MacMahon 1994).

Thus, it is probably logical to conjecture that physical dormant seeds might be a dominant trait in dry ecosystems mainly for two reasons. First, the lower humidity, seasonal rainfall, and high temperatures prevalent in these ecosystems would dry the seeds to lower moisture level. Second, long-term persistence in soil is an adaptive mechanism for the successful establishment of seeds in dry environments due to the limited window of opportunity for germination compared with moist habitats where water and appropriate temperature required for germination is available throughout the year. However, there are no empirical data to support this assertion. The purpose of this contribution was to determine if there is a relationship between the distribution of PY species and climatic conditions by examining the data available on seed dormancy on various ecosystems. Our secondary hypothesis was to examine if the occurrence of this trait is more prevalent in any particular life-form.

\section{Methods and data set}

Following Walther's (1979) description of vegetation zone (with some modifications), the data available on the seed dormancy types on different vegetation zones was summarized by Baskin and Baskin (2014). In this scheme, the vegetation zones of the world were divided into two broad categories: (1) tropical and subtropical zones and (2) temperate and arctic zones. The tropical and subtropical zone were further subdivided into (1) evergreen rain forests of the low lands and mountainsides; (2) semi-evergreen and deciduous forests; (2a) dry woodlands, natural savannas or grasslands; (3) hot semi-deserts and deserts, poleward up to latitudes of $35^{\circ} \mathrm{N}$ and $35^{\circ}$. Likewise, temperate and arctic zones were subdivided into (1) schlerophyllous woodlands with winter rain; (2) moist warm temperature woodlands; (3) deciduous (nemoral) forests; (4) steppes; (4a) semi-deserts and deserts with cold winters; (5) boreal coniferous zone; (6) tundra; (7) mountains. From the details presented by Walther's (1979) and Tweddle et al. (2003) the data on these vegetation zones with decreasing mean rainfall towards increasing dry season were separately analyzed for tropical and temperate regions (see Tweddle et al. 2003).

From data presented in Baskin and Baskin (2014) and other recent publications and personal communications, we were able to use the information on the type of dormancy available on 


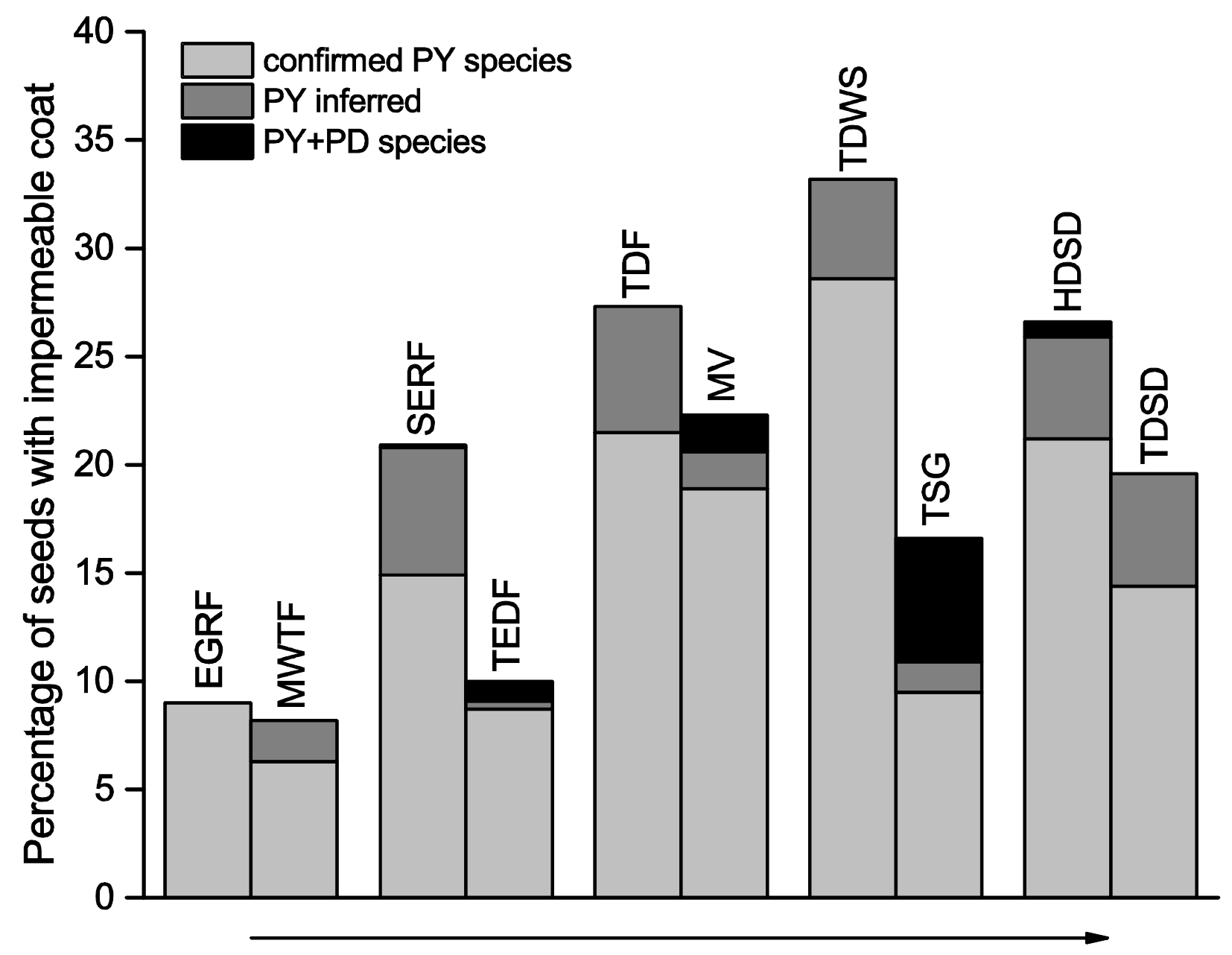

\section{moist to dry climate zones in temperate and tropics}

Figure 1. Percentage of seeds with impermeable seed coat in tropics (left side bar of each group) and temperate (right side bar of each group) with climate becoming drier from left to right. The x-axis does not have any linear relationship with each plot. EGRF, tropical ever green rain forest; SERF, tropical semi ever green rain forest; TDF, tropical deciduous forest; TWDS, tropical dry woodlands, natural savannas and grasslands; HDSD, tropical hot and semi-hot deserts; MWTF, moist wet temperate forest; TEDF, temperate evergreen deciduous forest; MV, mattoral vegetation; TSG, temperate steppes or grassland; TDSD, temperate deserts and semi-deserts with cold winter.

13, 792 species for this analysis. The number of PY species in each vegetation was summed and the percentage was determined. In the entries added by our literature search and personal communications, we classified a species to produce PY seeds only when $50 \%$ or more of the seeds were impermeable at full maturity or after dried to a moisture content below $10 \%$ f.wb. However, in many previous studies, concluding a species produce PY seeds is often confounded by the lack of imbibition test and there are several 'inferences' made by Baskin and Baskin (2014) for such species. Although there is potential risk in performing this analysis by including these species as definitive PY, because future imbibition test may add or remove those species from the group of PY species, the smaller number of species in this 'inferred' category compared with the total number of species used in this study, would not alter the results significantly. In addition, some species produce seeds with $\mathrm{PY}+\mathrm{PD}$, but for the purpose of this analysis, we treat them as PY seeds, as these seeds also have impermeable seed coat.

\section{Results and discussion}

Our analysis clearly shows that PY is more common in dry ecosystems than in wet regions. In a tropical ecosystem, evergreen rain forest receiving high rainfall throughout the year has $9 \%$ of the PY species compared with $33.1 \%$ in dry woodlands, where the conditions are completely dry (Fig 1). Similarly, the moist warm temperate woodlands and deciduous forests of the temperate ecosystem that are moist throughout the year have less than $10 \%$ of PY species compared with more than $15 \%$ at dry vegetation zone (Fig 1). However, it was not possible to clearly conclude that the driest vegetation zones have the higher percentage of PY. For example, the hot semi-deserts and deserts of the tropical zone have $25.6 \%$ PY species compared with $33.1 \%$ at dry woodlands (Fig 1). A similar trend can also be seen for temperate 


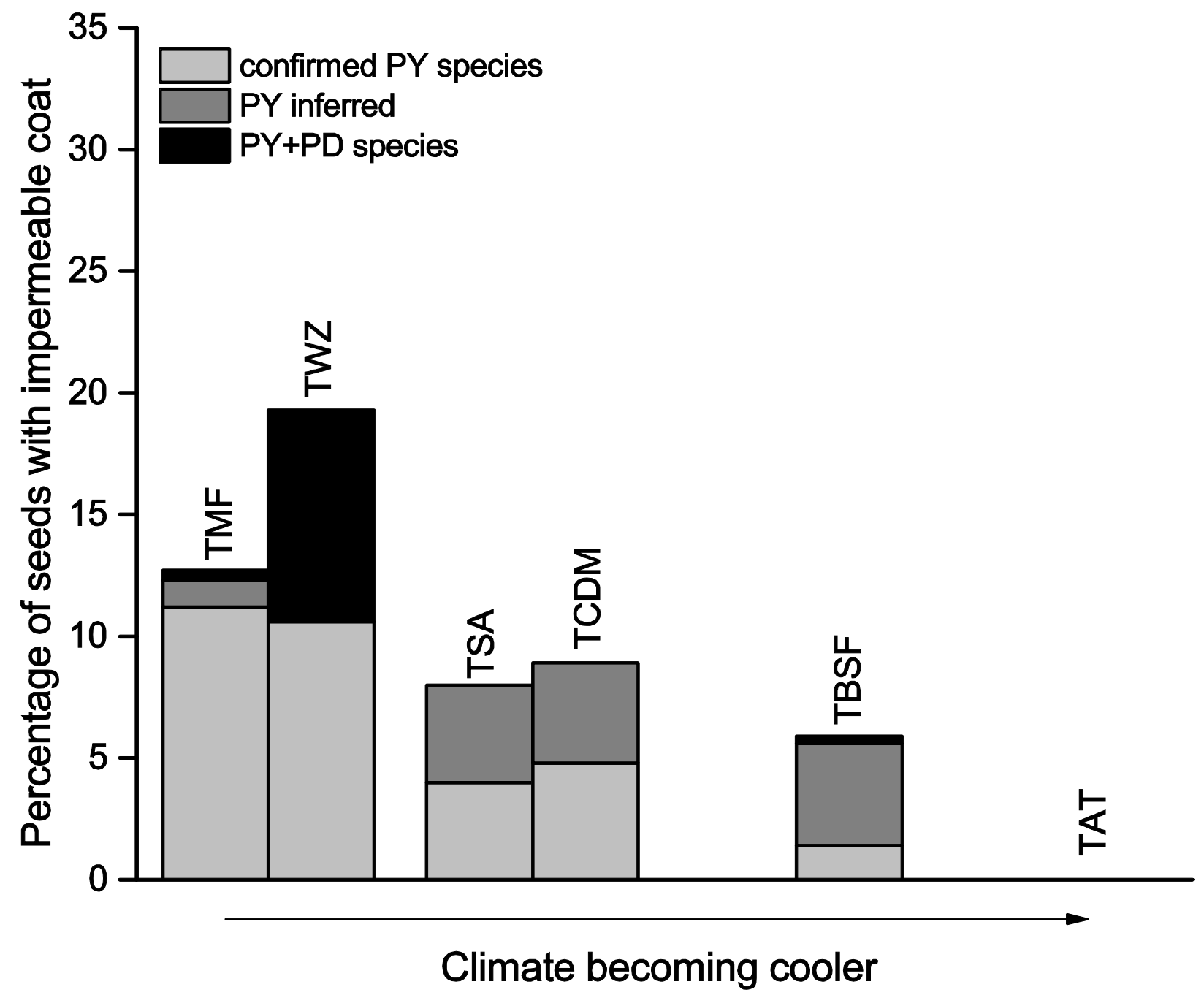

Figure 2. Percentage of seeds with impermeable seed coat in tropics (left side bar of each group) and temperate (right side bar of each group) with climate becoming cooler from left to right. TMF, tropical montane forest; TSA, tropical sub alpine; TWZ, temperate wood zone; TCDM, temperate coniferous dominated montane; TBSF, temperate boreal coniferous and sub-alpine forests; TAT, temperate arctic and alpine tundra.

Table 1. Distribution of physical dormancy in various life-forms across tropical and temperate ecosystems. Values given in parenthesis are the percentage of inferred species. NDE- no details exist.

\begin{tabular}{lcc} 
& Life form & Percentage of physical dormant seeds \\
\cline { 2 - 3 } & Tropical ecosystem & Temperate ecosystem \\
\hline Trees & $15.2(5)$ & $6.8(0.9)$ \\
Shrubs (and bamboos) & $27.8(6.2)$ & $18.9(0.2)$ \\
Lianas and vines & $22.3(3)$ & $20(3.4)$ \\
Herbs and epiphytes & $21.7(4)$ & $10.5(2.4)$ \\
Weeds & $18.2(0)$ & $26.9(0)$ \\
Annuals & $23.5(1.3)$ & NDE \\
Non-weeds & NDE & $8.8(1.2)$ \\
Forbs & NDE & $19.8(1.7)$ \\
Graminoids & NDE & 0 \\
\hline
\end{tabular}

deserts and semi-deserts that produce $19.5 \%$ of PY species compared with $22.3 \%$ at Matorral (Fig 1). This lack of trend might be possibly attributed to the paucity of data on many vegetation zones. The occurrence of PY also declines with decreasing temperature both in tropics and temperate zones. It is certainly clear that high proportion of PY seeds is found in tropical montane forest (12.7\%) and northern temperate woodland (18.3\%) compared with high altitude vegetation (Fig 2). 
Both the vegetation with high PY species occurs at a lower altitude and have dry season compared to the high altitude ecosystem, where temperature and the duration of warm period available for seed maturation diminish (Körner 2003).

Based on this analysis and the previous work by Tweddle et al. (2003), it can be observed that when the climate becomes drier the desiccation-sensitive seeds decreases but the proportion of species with impermeable seed coat increases (Fig 1). However, both these assertions have many exceptions with some desiccationsensitive occurring in the dry ecosystem and impermeable seed coat in the moist ecosystem. In this regard, it is worth noting that desiccationsensitive seeds that colonize in dry tropical ecosystem develops and matures during the wetrainy season (Daws et al. 2005; Dickie and Pritchard 2002; Jayasuriya et al. 2013; Pammenter and Berjak 2000), with conditions close to the moist environment. In tropical African drylands, for example, Syzygium cumini, Trichilia emetica, and Vitellaria paradoxa produce recalcitrant seeds, but the seed development and dispersal occurs during the moist season (Pritchard et al. 2004). Since the majority of the recalcitrant seeds are non-dormant, immediate germination allows the seeds to establish in to seedling before the return of dry conditions (Hill et al. 2012). However, it is difficult to disentangle if PY seeds occurring in moist environments of the tropics and temperate ecosystem is restricted to the open sites or at the edges of vegetation transformation, where the conditions are drier. Given that impermeability is induced only after moisture content of the seeds drops below at least $15 \%$ f.wb. it is plausible to conclude that none of the desiccation-sensitive seeds have PY, despite some species were theoretically concluded to be exceptions e.g Alectryon excelsum Gaert. (Sapindaceae) (see Tweddle et al. 2003). Furthermore, PY appears to be a highly conserved trait in seeds. A population of PY plants growing in moist environments producing non-dormant seeds because the moisture content remained high above a threshold level to induce impermeability, could produce dormant seeds in subsequent generations when the climate become drier (Nichols et al. 2009). Thus, testing the proposition that PY species in moist environments might occur in dry micro-sites requires very considerable work.

In spite of less information available PY species distribution within particular vegetation, the highest frequency of PY seeds in dry and less rainfall ecosystem (Fig 1) suggest that this trait might have multiple advantages in these conditions. As explained above, the obvious fitness benefit for PY seeds is the ability to establish longterm persistence of seeds in soil. However, although long-term persistence of seeds in these environments increases the colonization ability of seeds, it reduces the opportunity to germinate during every growing season (Fenner and
Thompson 2005; Rees 1994). Conversely, PD also regulates the germination timing and presents an opportunity to germinate every growing season (Paulsen et al. 2013). Given that PY is evolved from PD species (Van Staden et al. 1989; Willis et al. 2014), the fitness advantages of this trait evolution must be under the selection pressure of environmental conditions. From an ecological point of view, the key difference between PD and PY seeds in regulating the germination timing may be linked to the habitat at which these traits operate. In ecosystems with dry and warm climate, after-ripening breaking physiological dormancy may be hastened during hightemperature and these seeds germinate during aseasonal rainfall and the seedlings die (Bazin et al. 2011; Schütz et al. 2002; Steadman et al. 2003). In contrast, dormancy break in physical dormant species occurs in two steps: (1) pre-conditioning, wherein seeds are conditioned from the soil temperature for dormancy break and (2) dormancy break, during which seeds actually open 'water-gap' allowing the water to enter internal structures (Jayasuriya et al. 2009; Jayasuriya et al. 2008; Taylor 2005). Thus, seeds with PD have increased the risk of germinating at the seasons other than growing season, but at least in the proportion of seeds opportunity to germinate arises every year. Whereas, seeds with PY wait for a long time but most likely germinate only during growing season because aseasonal rainfall does not stimulate germination. By producing both permeable and impermeable seeds, the fitness of species establishment is increased.

Because the non-dormant seeds adapted to moist environments germinate soon after dispersal, the time for pathogen or fungi damaging the seeds is minimal. However, the PD seeds in the dry ecosystem are highly susceptible to fungal attack due to the risk of wetting during aseasonal rainfall, as a consequence these seeds are likely to invest more towards physical defense (Dalling et al. 2011). Thus, the nature of impermeable coat preventing the internal structures of PY seeds from pathogen and fungal attack, can be viewed as an adaptive mechanism in the dry environments. Furthermore, by maintaining impermeable seed coat until growing season prevents the risk of seed predation because of no volatile compounds emitted by PY seeds (Paulsen et al. 2013; Paulsen et al. 2014). Seed predation accounts for the greater loss of seeds in the soil, as the predators consume many of the seeds and bury the remainder in a place that is not favorable for germination (Hulme 1998; Thompson 2000). Generally, predators use the smell of the chemicals emitted from seeds as olfactory cues to detect the seeds in soil and after the seed coat becomes impermeable no such compounds are emitted until dormancy is broken. Although in a dry state ( $<6 \%$ moisture content) PD seeds also do not emit volatile substances (Vander Wall 1993; Vander Wall 1995), seeds shed from 
parent plant are not always this dry. Further, dry environments pose a significant risk to PD being found during aseasonal rainfall or early rainy season because of imbibition, despite being dormant. Thus, it can be assumed that such a complex interaction of impermeable seed coat and predation indicate that PY can be a highly valuable trait in dry environments.

The limited number of PY and the complete absence of desiccation-sensitive seeds in high altitude suggests that both these traits do not provide significant fitness benefits for species establishment (Fig 2; Tweddle et al, 2003). An increase in altitude decreases temperature both in tropics and temperate, but the severity of conditions may differ between latitudes (Lütz 2011). There is now comprehensive evidence available to show that many species of high altitude ecosystem shed seeds during the end of autumn. Immediate germination is highly unlikely due to the harsh winter conditions following autumn (Billings and Mooney 1968; Bliss 1958; Jaganathan et al. 2015; Körner 2003). The prevailing low temperature during winter not only turns out to be unfavorable for desiccation sensitive seeds which are undergoing germination process but also kill them, explaining why desiccation sensitive seeds are completely absent in this ecosystem (Roberts and Ellis 1989; Walters et al. 2013). Most of the species adapted to these environments must also have the ability to form long-term persistence bank for species colonization because of infrequent return of germination conditions. Yet, PY is not common in high altitude ecosystem (Fig 2) and most of the seeds tend to have PD. The lower temperature and higher relative humidity during maturation could maintain the moisture content at levels higher than those required for inducing impermeability. Thus, by collecting seeds from families producing PY species and drying them would reveal important insights on this area. Secondly, the fact that germination happens immediately after PY is broken and the seeds with PY cannot cycle between dormant and non-dormant state explains the reason behind more species with $\mathrm{PD}$ in this ecosystem (Baskin and Baskin 2014). That is, species with PD breaking dormancy by coldstratification during winter have increased the chance for germination every year, but if the growing season turns out to be unfavorable these seeds enter dormancy again.

There is a significant difference in the distribution of PY across various life-forms (Table 1). In general, PY is less commonly found in trees, particularly in the temperate ecosystem. It is of interest to note that, none of the trees occurring in boreal and north temperate subalpine forests, conifer dominated montane and woodland zone of temperate ecosystem produce PY seeds. Tweddle et al. (2003) observed that the non-pioneer trees of evergreen rain forest have more desiccationsensitive seeds compared with no desiccation- sensitive seeds in pioneer taxa. This could be viewed as an adaptive mechanism, as seeds of pioneer species must persist in soil for some years and having a desiccation-sensitive seed would initiate germination immediately after landing on the soil. However, PY seeds are found in both pioneer and non-pioneer trees of the evergreen rain forest. The apparent reason and ecological significance for this are difficult to explain until more details are available on the distribution of physical dormancy in relation to micro-climates. One important question is whether the PY pioneer non-pioneer tree species are found at the edges of vegetation change, plausibly climate becoming drier. The location of maturation site is likely to have a profound effect on PY and PD (Jaganathan 2016; Steadman et al. 2004). Secondly, the influence of seed maturing season in producing dormant seeds in general and PY in particular have also been extensively documented (e.g. Salazar et al. 2011). The available data also shows that no herbs of the evergreen rain forest, vines and perennials of hot semi-deserts and deserts are known to have PY seeds (Table 1). Further, the present analysis revealed that PY can be commonly seen in shrubs, lianas and vines, herbs and epiphytes and weeds of both temperate and tropical ecosystems. One simple explanation for the less occurrence of PY in tress of the temperate ecosystem may be that most of the trees of boreal vegetation are gymnosperms. Since PY does not occur in any gymnosperm species, the proportion of tree species with PY declines towards conifer and boreal forest. Moreover, trees also decline with increasing altitude and latitude, which might also be the reason for this trend.

Although Tweddle et al. (2003) suggested that the proportion of species with dormant seeds increase with climate aridity, their data set included only 886 species. However, with the mounting body of literature, it is becoming increasingly evident that many of the number of species with dormant seeds increases with the geographical distance from equator because of seasonal variation in climate (Bewley et al. 2013). The trend that PY increases with climate becoming drier indicate this trait could have multiple benefits in species establishment in several ecosystems (see above). More efforts on documenting the distribution of seeds with impermeable coat could help understand the ecological significance of this trait at community level. The work by Jayasuriya et al. (2013) emphasizes the need for further survey of PY species in dry ecosystems. Whilst the summer temperature and diurnal temperature fluctuations in tropics are known to act as important cues in breaking dormancy (Hagon 1971; Jayasuriya et al. 2008; McDonald 2000; Moreno-Casasola et al. 1994; Quinlivan 1968; Renzi et al. 2016), the factors that make seeds permeable in temperate and moist environment are less well known. Although burial experiments in temperate ecosystems indicated 
that PY seeds use winter temperature to break dormancy (probably during winter) and germinate in spring (Van Assche et al. 2003), some studies showed that temperature prevailing in these ecosystems do not break dormancy (Baskin et al. 1998). Despite this, the moisture content of seeds in those studies was not determined, thus limiting our ability to draw more apparent conclusion (Jaganathan 2016). In particular, how PY in moist and dry ecosystems become sensitive and what cues break dormancy must be studied in detail using temperatures and conditions prevailing in natural environment, paying some attention to the moisture content of the seeds. Such studies would inform us about the ecological adaptation and significance of PY.

\section{Summary of main findings}

From the dataset compiled and the relevant literature available, the following conclusions can be drawn. The number of species with PY in tropics (19\%) is higher than the number of PY species in the temperate ecosystem (15\%). However, in both tropics and temperate, there is a clear trend that PY is less common in moist and low-temperature vegetation zones compared with dry and high-temperature vegetation. In tropics, PY is more prevalent in dry woodlands (33\%) and tropical deciduous forests $(27.3 \%)$ compared with the evergreen rain forest (9\%). Similarly, in the temperate zone, dry vegetation with seasonal rainfall such as Matorral (22.3) and deserts (19.5\%) have a higher number of PY species compared with moist warm woodlands (8.1\%) and deciduous forest (9\%). In the moist wet climates, species with desiccation-sensitive seeds occur predominantly as the conditions for growing are prevalent most of the year and dormancy mechanisms would obscure germination. Thus, the seeds that are desiccation sensitive and impermeable seed coats are selected for climates with contrasting conditions. Interestingly, although PY is a trait found in various life-forms, it appears to be less common in trees, particularly of the temperate zone.

\section{Acknowledgement}

I sincerely thank Ms. Xiao Qun for her help throughout this project.

\section{Competing Interest}

The authors declare that they have no competing interests.

\section{References}

Barrett-Lennard, R., Gladstones, J. 1964. Dormancy and hard-seededness in Western Australian serradella (Ornithopus compressus L.). Aust J Agric Res 15:895-904 https://doi.org/10.1071/AR9640895
Baskin, C.C., Baskin, J.M. 2014. Seeds: ecology, biogeography, and evolution of dormancy and germination. Second edn. Elsevier, San Diego, USA

Baskin, J.M., Baskin, C.C. 2004. A classification system for seed dormancy. Seed Sci Res 14:1-16 https://doi.org/10.1079/SSR2003150

Baskin, J.M., Baskin, C.C., Li, X. 2000. Taxonomy, anatomy and evolution of physical dormancy in seeds. Plant Species Biol 15:139-152 https://doi.org/10.1046/j.1442-1984.2000.00034.x

Baskin, J.M., Nan, X., Baskin, C.C. 1998. A comparative study of seed dormancy and germination in an annual and a perennial species of Senna (Fabaceae). Seed Sci Res 8:501-512 https://doi.org/10.1017/S0960258500004475

Bazin, J., Batlla, D., Dussert, S., El-Maarouf-Bouteau. H., Bailly, C. 2011. Role of relative humidity, temperature, and water status in dormancy alleviation of sunflower seeds during dry afterripening. $J$ Exp Bot 62:627-640 https://doi.org/10.1093/jxb/erq314

Bewley, J.D., Bradford, K., Hilhorst, H., Hiro, N. 2013. Seeds: physiology of development, germination and dormancy. Springer Science \& Business Media, London https://doi.org/10.1007/978-1-4614-4693-4

Billings, W.D., Mooney, H.A. 1968. The ecology of arctic and alpine plants. Biol Rev 43:481-529 https://doi.org/10.1111/j.1469-185X.1968.tb00968.x

Bliss, L. (1958) Seed germination in arctic and alpine species. Arctic 11:180-188 https://doi.org/10.14430/arctic3743

Chambers, J.C., MacMahon, J.A. 1994. A day in the life of a seed: movements and fates of seeds and their implications for natural and managed systems. Ann Rev Ecol Syst 25:263-292 https://doi.org/10.1146/annurev.es.25.110194.0014 03

Dalling, J.W., Davis, A.S., Schutte, B.J., Elizabeth Arnold, A. 2011. Seed survival in soil: interacting effects of predation, dormancy and the soil microbial community. $J \quad$ Ecol $99: 89-95$ https://doi.org/10.1111/j.1365-2745.2010.01739.x

Daws, M., Garwood, N., Pritchard, H. 2005. Traits of recalcitrant seeds in a semi-deciduous tropical forest in Panamá: some ecological implications. Functional Ecol 19:874-885 https://doi.org/10.1111/j.1365-2435.2005.01034.x

Dickie, J.B., Pritchard, H.W. 2002. Systematic and evolutionary aspects of desiccation tolerance in seeds. In: Black, M., Pritchard, H.W. (eds) Desiccation and survival in plants: drying without dying. Wallingford, UK: CAB International. Wallingford, UK, pp 239-259 https://doi.org/10.1079/9780851995342.0239

Egley, G. 1979. Seed coat impermeability and germination of showy crotalaria (Crotalaria spectabilis) seeds. Weed Science 27:355-361

Egley, G., Chandler, J.M. 1983. Longevity of weed seeds after 5.5 years in the Stoneville 50 -year buriedseed study. Weed Science 31:264-270

Fenner, M., Thompson, K. 2005. The ecology of seeds. Cambridge University Press.

Geneve, R.L. 2009. Physical seed dormancy in selected Caesalpinioid legumes from eastern. North America Propagation of Ornamental Plants 9:129134 https://doi.org/10.1017/CBO9780511614101

Gama-Arachchige, N.S., Baskin, J.M., Geneve, R.L., Baskin, C.C. 2011. Acquisition of physical dormancy and ontogeny of the micropyle-watergap complex in developing seeds of Geranium 
carolinianum (Geraniaceae). Ann Bot 108:51-64 https://doi.org/10.1093/aob/mcr103

Gama-Arachchige, N.S., Baskin, J.M., Geneve, R.L., Baskin, C.C. 2013. Identification and characterization of ten new water gaps in seeds and fruits with physical dormancy and classification of water-gap complexes. Ann Bot 112:69-84 https://doi.org/10.1093/aob/mct094

Garwood, N.C. 1983. Seed germination in a seasonal tropical forest in Panama: a community study. Ecological Monographs 53:159-181 https://doi.org/10.2307/1942493

Gladstones, J.S. 1958. The influence of temperature and humidity in storage on seed viability and hardseededness in the west Australian Blue Lupin, Lupinus digitatus Forsk. Aust J Agric Res. 9:171181. https://doi.org/10.1071/AR9580171

Hagon, M. 1971. The action of temperature fluctuations on hard seeds of subterranean clover. Aust J Exp Agric 11:440-443 https://doi.org/10.1071/EA9710440

Hay, F.R., Smith, R.D., Ellis, R.H., Butler, L.H. 2010. Developmental changes in the germinability, desiccation tolerance, hardseededness, and longevity of individual seeds of Trifolium ambiguum. Ann Bot 105:1035-1052 https://doi.org/10.1093/aob/mcq037

Hill, J.P., Edwards, W., Franks, P.J. 2012. Size is not everything for desiccation-sensitive seeds. $J$ Ecol 100:1131-1140 https://doi.org/10.1111/j.13652745.2012.02005.x

Hong, T.D., Linington, S., Ellis, R.H. 1998. Compendium of information on seed storage behaviour. Vols 1 and 2. Royal Botanic Gardens, Kew,

Hudson, A.R., Ayre, D.J., Ooi, M.K. 2015. Physical dormancy in a changing climate. Seed Sci Res 23:66-81 https://doi.org/10.1017/S0960258514000403

Hulme, P. (1998) Post-dispersal seed predation and seed bank persistence. Seed Sci Res 8:513-519 https://doi.org/10.1017/S0960258500004487

Jaganathan, G.K., Dalrymple, S.E., Liu, B. 2015. Towards an understanding of factors controlling seed bank composition and longevity in the alpine environment. Bot Rev 81:70-103 https://doi.org/10.1007/s12229-014-9150-2

Jaganathan, G.K. 2016. Influence of maternal environment in developing different levels of physical dormancy and its ecological significance. Plant Ecol 217:71-79 https://doi.org/10.1007/s11258-015-0560-y

Jaganathan, G.K., Yule, K., Liu, B. 2016. On the evolutionary and ecological value of breaking physical dormancy by endozoochory. Pers Plant Ecol Evol Syst 22: 11-22 https://doi.org/10.1016/j.ppees.2016.07.001

Jayasuriya, K.M.G.G., Wijetunga, A.S., Baskin, J.M., Baskin, C.C. 2013. Seed dormancy and storage behaviour in tropical Fabaceae: a study of 100 species from Sri Lanka. Seed Sci Res 23:257-269 https://doi.org/10.1017/S0960258513000214

Jayasuriya, K.M.G.G., Baskin, J.M., Baskin, C.C. 2009. Sensitivity cycling and its ecological role in seeds with physical dormancy. Seed Sci Res 19:3-13 https://doi.org/10.1017/S096025850818730X

Jayasuriya, K.M.G.G., Baskin, J.M., Baskin, C.C. 2008. Cycling of Sensitivity to Physical Dormancy-break in Seeds of Ipomoea lacunosa (Convolvulaceae) and Ecological Significance. Ann Bot 101:341-352 https://doi.org/10.1093/aob/mcm285
Khurana, E., Singh, J. 2001. Ecology of seed and seedling growth for conservation and restoration of tropical dry forest: a review. Environmental conservation https://doi.org/10.1017/S0376892901000042

Körner, C. 2003. Alpine plant life: functional plant ecology of high mountain ecosystems. Springer Verlag, https://doi.org/10.1007/978-3-642-18970-8

Long, R. L., Gorecki, M. J., Renton, M., Scott, J. K., Colville, L., Goggin, D. E., Commander, L. E., Westcott, D. A., Cherry, H. and Finch-Savage, W. E. 2015. The ecophysiology of seed persistence: a mechanistic view of the journey to germination or demise. Biol Rev 90:31-59 https://doi.org/10.1111/brv.12095

Mai-Hong, T., Hong, T.D., Hien, N.T., Ellis, R.H. 2003. Onset of germinability, desiccation tolerance and hardseededness in developing seeds of Peltophorum pterocarpum (DC) K. Heyne (Caesalpinioideae). Seed Sci Res 13:323-327 https://doi.org/10.1079/SSR2003149

McDonald, C.K. 2000. Variation in the rate of hard seed breakdown of twelve tropical legumes in response to two temperature regimes in the laboratory. Aust J Exp Agric 40:387-396 https://doi.org/10.1071/EA99099

Moreno-Casasola, P., Grime, J.P., Martínez, M.L. 1994. A comparative study of the effects of fluctuations in temperature and moisture supply on hard coat dormancy in seeds of coastal tropical legumes in Mexico. J Trop Ecol 10:67-86 https://doi.org/10.1017/S0266467400007720

Nichols, P., Cocks, P., Francis, C. 2009. Evolution over 16 years in a bulk-hybrid population of subterranean clover (Trifolium subterraneum L.) at two contrasting sites in south-western Australia. Euphytica 169:31-48 https://doi.org/10.1007/s10681-009-9906-7

Pammenter, N., Berjak, P. 2000. Evolutionary and ecological aspects of recalcitrant seed biology. Seed Sci Res 10:301-306 https://doi.org/10.1017/S0960258500000349

Paulsen, T.R., Colville, L., Kranner, I., Daws, M.I., Högstedt, G., Vandvik, V., Thompson, K. 2013. Physical dormancy in seeds: a game of hide and seek?. New Phytol 198:496-503 https://doi.org/10.1111/nph.12191

Paulsen, T.R., Högstedt, G., Thompson, K., Vandvik, V., Eliassen, S. 2014. Conditions favouring hard seededness as a dispersal and predator escape strategy. $\quad J \quad$ Ecol 102:1475-1484 https://doi.org/10.1111/1365-2745.12323

Pritchard, H.W., Daws, M.I., Fletcher, B.J., Gaméné, C.S., Msanga, H.P., Omondi, W. 2004. Ecological correlates of seed desiccation tolerance in tropical African dryland trees. Am $J$ Bot 91:863-870 https://doi.org/10.3732/ajb.91.6.863

Quinlivan, B.J. 1968. The softening of hard seeds of sanplain lupin (Lupinus varius). Aust I Agric Res 19:507-515 https://doi.org/10.1071/AR9680507

Rees, M. 1994. Delayed germination of seeds: a look at the effects of adult longevity, the timing of reproduction, and population age/stage structure. Am Nat 144:43-64 https://doi.org/10.1086/285660

Renzi, J.P., Chantre, G.R., Cantamutto, M.A. 2016. Effect of water availability and seed source on physical dormancy break of Vicia villosa ssp. Villosa. Seed Sci Res 26:254-263 https://doi.org/10.1017/S096025851600012X

Roberts, E., Ellis, R. 1989. Water and seed survival. Ann Bot

63:39-52 
https://doi.org/10.1093/oxfordjournals.aob.a08772 7

Rolston, M.P. 1978. Water impermeable seed dormancy. Bot Rev 44:365-396 https://doi.org/10.1007/BF02957854

Salazar, A., Goldstein, G., Franco, A.C., Miralles-Wilhelm, F. 2011. Timing of seed dispersal and dormancy, rather than persistent soil seed-banks, control seedling recruitment of woody plants in Neotropical savannas. Seed Sci Res 21:103-116 https://doi.org/10.1017/S0960258510000413

Sautu, A., Baskin, J.M., Baskin, C.C., Condit, R. 2006. Studies on the seed biology of 100 native species of trees in a seasonal moist tropical forest, Panama, Central America. Forest Ecol Manag 234:245-263 https://doi.org/10.1016/j.foreco.2006.07.006

Schütz, W., Milberg, P., Lamont, B. 2002. Seed Dormancy, After-ripening and Light Requirements of Four Annual Asteraceae in South-western Australia. Ann Bot 90:707-714 https://doi.org/10.1093/aob/mcf250

Shen-Miller, J., Mudgett, M.B., Schopf, J.W., Clarke, S., Berger, R. 1995. Exceptional seed longevity and robust growth: ancient sacred lotus from China. Am $\quad$ B $\quad B o t \quad 82: 1367-1380$ https://doi.org/10.2307/2445863

Steadman, K.J., Crawford, A.D., Gallagher, R.S. 2003. Dormancy release in Lolium rigidum seeds is a function of thermal after-ripening time and seed water content. Functional Plant Biol 30:345-352 https://doi.org/10.1071/FP02175

Taylor, G.B. 2005. Hardseededness in Mediterranean annual pasture legumes in Australia: a review Aust $J$ Agric Res 56:645-661 https://doi.org/10.1071/AR04284

Thompson, K. 2000. The functional ecology of soil seed banks. In: Fenner, M. (ed) Seeds: the ecology of regeneration in plant communities. Vol 2. CABI pp 215-235 https://doi.org/10.1079/9780851994321.0215

Tweddle, J.C., Dickie, J.B., Baskin, C.C., Baskin, J.M. 2003. Ecological aspects of seed desiccation sensitivity. $J$ Ecol 91:294-304 https://doi.org/10.1046/j.13652745.2003.00760.x
Van Assche, J.A., Debucquoy, K.L., Rommens, W.A. 2003. Seasonal cycles in the germination capacity of buried seeds of some Leguminosae (Fabaceae). New Phytol 158:315-323 https://doi.org/10.1046/j.1469-8137.2003.00744.x

Van Staden, J., Manning, J., Kelly, K. 1989. Legume seedsThe structure: function equation. In: Stirton, C.H., Zarucchi, J.L. (ed) Advances in legume biology. Monographs in Systematic Botany from the Missouri Botanical Garden, pp 417-450

Vander Wall, S.B. 1993. Seed Water Content and the Vulnerability of Buried Seeds to Foraging Rodents. Am Mid Nat 129:272-281 https://doi.org/10.2307/2426508

Vander Wall, S.B. 1995. Influence of substrate water on the ability of rodents to find buried seeds. $J$ Mammalogy 76:851-856 https://doi.org/10.2307/1382753

Vázquez-Yanes, C., Orozco-Segovia, A. 1993. Patterns of seed longevity and germination in the tropical rainforest. Ann Rev Ecol Syst 24:69-87 https://doi.org/10.1146/annurev.es.24.110193.0004 41

Walters, C., Berjak, P., Pammenter, N., Kennedy, K., Raven, P. 2013. Preservation of recalcitrant seeds. Science https://doi.org/10.1126/science.1230935

Walther, H. 1979. Vegetation of the Earth and Ecological systems of the Geo-Bioshpere. Second ed. SpringerVerlag, Berlin https://doi.org/10.1007/978-1-46840468-5

Willis, C.G., Baskin, C.C., Baskin, J.M., Auld, J.R., Venable, D.L., Cavender-Bares, J., Donohue, K., de Casas, R.R. 2014. The evolution of seed dormancy: environmental cues, evolutionary hubs, and diversification of the seed plants. New Phytol 203:300-309 https://doi.org/10.1111/nph.12782 